\title{
Radical Markets by Eric Posner and E. Glen Weyl: A Review Essay"
}

\author{
DAVID K. LEVINE*
}

At a time when standards of living have improved more than any time in history, this book makes a proposal for radical change. It is based-loosely—on market design principles. The plan for attacking overlapping ownership is reasonably well thought out. Most of the book, however, proposes to use mechanisms designed for a narrow purpose; to attack real or imagined problems that they are ill-suited to solve. I conclude that while market design has a lot to offer when properly applied, the proposals here are not sufficiently well thought out to constitute a serious plan of action.(JEL D44, D47, D72, D82, P14)

\section{Introduction}

$\mathrm{T}$ he world in general is becoming a better place. Standards of living are rising; poverty, hunger, and warfare are on the decline. Our ability to communicate, to learn, to entertain, and to be entertained are increasing at a phenomenal rate. The climate may be warming, but fortunately it is doing so at a very slow pace. At the same time the speed of progress is uneven-especially in the historically rich parts of the world. Here we see stagnating wages for some, increasing

\footnotetext{
* European University Institute, Robert Schuman Center for Advanced Studies, and Washington University in St. Louis. I am grateful to conversations with Alessandra Casella and Peter Cramton. I owe a particular debt of gratitude to Steven Durlauf for his exceptional editorial work. As always, should I be caught or killed, they disavow any responsibility for the thoughts expressed here.

${ }^{\dagger}$ Go to https://doi.org/10.1257/jel.20191533 to visit the article page and view author disclosure statement(s).
}

incidence of mental illness, increased use of dangerous recreational drugs, and decreasing numbers of poorly employed young people who are asked to support increasing numbers of old people. Populism is rising, democracy is threatened, and there is political anger and anxiety toward immigrants, trade, and experts. Nevertheless, moral considerations propel us to the view that the great improvement among the many poor must outweigh the harm to the few rich: the overall picture is extremely positive. There is not a case for substantial, let alone radical, change. Those rich countries that have introduced substantial change-the United States through President Donald Trump's trade wars, the United Kingdom through Brexit-are finding that these cures are worse than the diseases, not only for the rest of the world, but for themselves as well. In this situation experts-economists and 
others-would probably be well advised to fight to protect our existing institutions and not to propose radical change.

The authors of Radical Markets clearly disagree. They see the current state of the world as intolerable and feel that radical change is needed. The book is thought provoking. They propose a range of reformssome radical indeed-revolving around the use of auctions in various forms. The book is written for a general audience and economists must surely communicate with the public. It is a good read of the sort needed to draw the nonspecialist. It is full of anecdotes and stories. These catch the eye and help us to understand. Policy, however, cannot be based on anecdotes and stories, but on reasoning and evidence. Does the book stand on solid ground?

While their proposals are radical, the book is more of a series of essays than a single coherent framework for reform, so I will discuss it one piece at a time. Each chapter attacks a particular class of social problems and suggests a radical solution. It is highly Western centric: the chapter on globalization focuses primarily on the ill will created in rich countries by migration from poor countries. The problems of institutional ownership of public firms and of "data slavery" scarcely exist outside the West. In many countries the problem with democracy is not that it works poorly, but that it does not exist. Nevertheless, we can ask: are these proposals a way forward from the (mild) malaise that has fallen over the West?

While each chapter is idiosyncratic, there is a commonality in all the chapters. Each essay illustrates a social problem through specific examples; it generalizes those examples to broader settings-sometimes a setting where the problem does not exist or is quite different; it examines existing institutions and proposed solutions as well as some historical facts. It suggests that existing institutions and proposals are defective. It then argues that with minor tweaks, solutions that work well in specific (and not necessarily relevant) circumstances solve much broader problems. Each of these tweaked solutions is marketed through an acronym or abbreviation: COST, QV, and VIP for their market, political, and immigration reforms. The benefits of each is discussed at length along with a few minor caveats.

You will gather that I do not think this book is what we need at this time. My fear is that proposing policies in inappropriate environments will cause them to become discredited in all environments. Hence, for example, storable votes are probably a useful innovation for committees and small groups of well-informed people. I shall argue the impact, if it were to be adopted for mass elections, would be to further reinforce unfortunate tendencies: to further empower special interests such as banks and bigots. If so, the idea might become discredited even for committees where it would be useful.

I will go through the book chapter by chapter indicating where I see problems. First to give an overview: the first chapter addresses the use of property, the second chapter addresses democracy, the third chapter addresses globalization, the fourth monopolization, and the final chapter addresses the ownership of data. The book begins with a preface, "The Auction Will Set You Free," and has two concluding chapters, one entitled "Conclusion: Going to the Root" and the other "Epilogue: After Markets." The final epilogue perhaps is indicative of the book, as the authors are skeptical that markets have benefits.

My bottom line is that I am in complete agreement with the authors that market design has a lot to offer. For those-perhaps not the general public, but certainly social scientists - who are interested in knowing what it does offer, I would recommend Haeringer's (2017) book. This is pitched at the advanced undergraduate level and has been successfully used to train MBA stu- 
dents. In it Haeringer studies numerous specific problems and shows how properly tailored solutions can lead to real improvements. Unlike the current book, Haeringer does not make broad hypothetical claims, but sticks to what is known and has been shown to work.

\section{Chapter 1: Property is Monopoly}

The chapter begins with a clear and careful description of the hold-up problem. Here, indeed, monopoly power is a problem. It then goes on to suggest that the hold-up problem is ubiquitous in ownership of property-that all property is monopoly and that the resulting misallocation might be on the order of 25 percent of income. Here as elsewhere the book is not strong on data. There is extensive research indicating that in some places at some times, misallocation is a problem possibly of this order of magnitude. Typically this research does not attribute misallocation to a problem with private property-generally the reverse. ${ }^{1]}$

There is debate within the profession about how well private property works when there are hold-up problems, private information, and externalities-with Ronald Coase having made the point that it is not self-evident that the private property fails in all these cases. There is a marvelous book by Michael Heller (2008) about hold-up problems: his description of the Quaker Oats "big inch" is unmissable. ${ }^{2}$ Nevertheless the economics profession does not generally view hold-up

\footnotetext{
1A good introduction the literature can be found in Restuccia and Rogerson (2017). They examine the difficulty of measurement and potential sources of misallocation. The evidence they discuss suggests that it is government interference in markets, rather than the normal functioning of markets, that leads to misallocation.

${ }^{2}$ In a promotion in 1955, Quaker Oats gave away 21 million deeds for one square inch of land it owned in Yukon, Canada. Needless to say whatever value the land had before it was owned in square inch increments was lost after.
}

and private information problems as ubiquitous nor externalities as insoluble. In many markets, ample substitutes are availablefor example in the housing market—so that monopoly power is not important. In some cases the market solves the hold-up problem relatively well-through tender offers and other ways of packaging properties. We have useful and existing remedies: imminent domain, Pigouvian taxes, and moderate regulation. We do not view private property as some sort of general monopoly problem that needs a general solution. That this might be a consensus does not make it true: but if the authors wish to argue that the problem is more widespread than commonly thought, they need to provide some solid evidencesomething they most certainly do not do.

Pushing on: the authors argue that the problem with the ubiquitous monopolies created by private property can be solved by a self-assessment wealth tax with mandatory sale at the self-assessed price. Self-assessment with a commitment to sell at that price is a useful and credible solution to problems involving assets for which there is substantial private information. This has been a particular problem for commercial real estate and for privately held businesses, where often artificially low transfer prices are used to avoid taxes. As the authors correctly say, top researchers such as Harberger (1965) and Cramton, Gibbons, and Klemperer (1987) have argued for self-assessment in these types of circumstances.

It is not immediately clear why a proposal for solving a particular private information problem should be viewed as a broad solution to a problem of ubiquitous monopoly, especially as the values of the bulk of assetsstocks and houses-are easy to determine. Nevertheless the authors propose that all property including improvements be subject to a 7 percent annual self-assessment wealth tax. I agree that this proposal, which they refer to as COST, is radical. 
The authors argue that a properly chosen self-assessment tax solves the problem of monopoly. I will say that I had a hard time understanding the argument through the examples given in the book, and in the end just worked it out for myself. Let us imagine that the problem of monopoly is ubiquitous where property is concerned. Consider a single unit of "property" valued by the owner at $v$. During a period of time, possibly a buyer may show up whose value is drawn from a distribution with $\operatorname{cdf} 1-G(w)$. Suppose that the owner is required at the beginning of the period to commit to sell to anyone who meets a price $p$ of her choosing, but has to pay a tax $G(v) p$. The number $G(v)$ is the "turnover rate," the probability of a higher valued user, which is assumed to be known although $G, v$ are not. Then the monopolist-the owner-has the objective function $G(p)(p-v)-G(v) p$ for which the first order condition is

$$
G^{\prime}(p)(p-v)+G(p)-G(v)=0,
$$

which is obviously satisfied at $p=v$ : the owner announces the true value so the asset is always sold to the highest valued user. By contrast, with a lower tax the owner will price some higher valued users out of the market, leading to an inefficiency.

There are a number of issues with this analysis. First, it relies on a very particular set of circumstances. Suppose-as is probably the case in the housing market-that turnover typically occurs not because someone comes along and fancies a particular house, but rather because the owner has decided to move. In effect the uncertainty here is about the owner valuation (low if, for example, the owner has taken a job in another location). Hence the tax is not based on the low probability of sale to a higher valued user but on the high probability the owner wants to sell. In this case it is easy to check that the owner, rather than setting price equal to their own value, will put price equal to the market value-there being a market for houses, after all. Under the COST proposal anyone who liked the house more than the market would be able to buy it, even if their value was much less than that of the owner. In this setting of uncertainty about owner value, we find that the COST scheme, rather than inducing efficient sales, leads to inefficient ones.

Second, the good being sold is a durable good. Absent some sort of law to the contrary, if the initially posted price is refused, the owner is free to set a lower price. This type of one-sided bargaining has been studied fairly extensively-for example, by Fudenberg, Levine, and Tirole (1985) and Gul, Sonnenschein, and Wilson (1986). It is known that as the delay between bargaining rounds goes to zero, the probability of sale goes to one and all the surplus goes to the buyer, just as is the case with the authors' proposal. It is unclear that there is any problem to be solved. Moreover, under the authors' proposal, the owner does not actually get their own value, rather their value minus the tax. This, needless to say, can be discouraging for investors who might later like to sell and the authors, recognizing this, suggest that the proper tax rate on self-assessed value should be somewhat lower than the "turnover rate."

There are other issues as well. First, the authors argue that their COST proposal would provide great benefit to the poor. A careful reading shows this has nothing to do with COST. It is based on the additional proposal that (part of) the revenue from COST is rebated lump sum. Any tax, progressive or not, for which the rich pay more in absolute terms than the poor that is a rebated lump sum will benefit the poor at the expense of the rich-indeed, that is the point of a negative income tax.

Second, the authors indicate that (i) assets can be clustered into groups, by the owner, that are indivisible; (ii) different assets should be taxed at different rates with higher rates 
for assets that turn over more frequently; (iii) taxes should be on the net rather than gross (so for homes, for example, only equity would be taxed); and (iv) improvements that could be ascertained using image analysis would get a subsidy. Such a scheme introduces numerous distortions:

- If the tax is on all net wealth, then everything must be taxed. For example, if only home equity is taxed, it would pay to take out the biggest possible mortgage and put the money in the stock market, which is not taxed. Reporting all income to the government is less than popular-the need to inventory and price everything you own is going to be less so. How much are your household items worth anyway?

- Demand for low turnover assets would increase relative to high turnover assets, as they are taxed at a lower rate. Worse: liquid assets turn over much more quickly than illiquid assets. Money, for example, turns over very quickly so this would be the Tobin tax to end all Tobin taxes. Literally implemented, the impact on trade would be severe, as nobody would be willing to hold liquid assets.

- Turnover rates are endogenous and there is an incentive to lower them.

The bottom line is that the turnover rate is meaningful only in limited contexts that are not common and should not be used as the basis for setting wealth tax rates. Moreover:

- There would be an incentive for "improvements" that make property unattractive to others.

- A bias would be created toward investments that are easily observed.

- There are undoubtedly many loopholes and we can be sure that a lot of time and effort would be spent figuring them out.
For example, my neighbor and I might collude. We set low prices for our property, each buy the other's, this creates delay, then we reverse. This way we keep our tax low and keep everyone else out of the market. Or perhaps a wife and husband trade the family house back and forth at a very low price. Of course we might not let the property go to the first comer, but allow others to bid, but then there will be a problem with straw bidders.

For all these problems the underlying issue is the same: this scheme is unworkable for the vast bulk of assets that are traded in thick markets and for which there is a clear market price. Take the stock market: prices fluctuate all the time and there are inframarginal owners who value the stock above the price and their value fluctuates all the time due to the movement of other stocks ... and so forth. From the proposals about institutional ownership, I gather the authors do not intend to abolish the stock market; and as indicated above, if the scheme is to work, everything must be taxed, including stocks. So, do you follow the procedure designed by houses? State a price at the beginning of the year you are willing to sell for and remain committed to that for the entire year regardless of circumstances and the state of the market? That seems an idea with many flaws. Or do you get to state a fluctuating price? In this case, unless you hear a takeover is being contemplated, you should state the market price, as you can always buy the stock back at that price. Here we have a complicated solution to a nonproblem: if we want a wealth tax on stock market holdings it is pretty straightforward to implement using market prices.

A one COST for all problems seems a step back from our current system. Private contracts allow a lot of flexibility to match particular circumstances. To take two examples: we have reverse mortgages for houses, 
and future markets for financial assets. It is true that budget balance and interim individual rationality constraints pose difficulties for contract design. In some cases, private contracts allow commitments that get around some of these problems. In other cases, carefully designed regulations can be helpful. COST will replace all these valuable and specialized solutions with a one-size-fits-all contract in which all prices must be committed by the seller in advance.

The bottom line is that for thick markets there is no monopoly power, it is difficult to get a self-assessment different than the market price, and trying to do so leads to important distortions. Hence self-assessment is out for these markets and we should just use market prices and avoid all the distortions introduced by COST. This means that a workable version of the COST proposal is to have a wealth tax based on market prices and just use COST for a few hard to price items.

At the end of the day the only substantive policy part of the authors' proposal is the 7 percent wealth tax. There is a huge theoretical and empirical literature on optimal taxation and tax incidence: from Harberger (1962) to Mirrlees (1971), Diamond (1998), Prescott (2004), Piketty and Saez (2013), Piketty (2014) and many many others. There is a heated debate about the importance of incentives, about issues of static inequality and the dynamic effect of tax rates on savings. Subtle differences between different types of taxes-income, consumption, and wealth-are debated. As it happens, the authors are not the only ones recently to propose a wealth tax: Piketty and several others have done the same, and indeed Piketty has also suggested the possibility of using very high rates (10 percent even). There is one rather important difference; Piketty proposes a graduated wealth tax with the idea that the very high taxes fall on those who have high rates of return. For example, he suggests that the very rich (as identified by the Forbes list) might have rates of return on the order of 6-7 percent and suggests taxing them perhaps at 5 percent. For others with much lower rates of return (1-2 percent being more typical) he suggests much lower rates. The point being, if the bulk of people who have rates of return on the order of 1-2 percent are taxed at the rate of 7 percent, the tax on capital income is on the order of 300 percent. I am unaware of any suggestion in the public finance literature that tax rates this high — for the middle class no less! — might be desirable. Underlying this is the fact that interest rates and subjective discount factors are important in assessing wealth taxes, and while we might expect some discussion of this in the book there is none.

There is of course a reason that general equilibrium models are ubiquitous in public finance: there is obviously no such thing as a 300 percent tax (at least not one that collects revenue) - and the rate of return has to adjust upward to compensate for such a high tax. This requires an enormous reduction in investment. If the COST proposal were to be implemented there would be two consequences. First, asset values would fall tremendously (the authors indicate at some point they think by two-thirds, but do not explain why). Second, investment would dry up. The 2008 financial crisis could look like a mere downward blip in comparison to the catastrophic effect of an across-the-board 7 percent annual wealth tax.

In fact it is rather worse than that. The very rich-who presumably the punitive tax is aimed at - can avoid it pretty well by moving operations to another country. Piketty recognizes this and argues that any serious wealth tax must be international - it cannot be purely national in scale. Posner and Weyl ignore this, one important example of the their lack of attention to implementation issues.

I indicated above that one of my concerns with poorly described and poorly thought 
out applications of a potentially useful idea is that it may discredit the idea entirely. A case in point is the end of the chapter where the authors propose that something like COST might be an improved way to allocate the electromagnetic spectrum. This is a serious proposal. But I wonder if after reading earlier broad and unsupported claims about murky policies and procedures anyone will be inclined to do so? Statements like this: "COST revenue ... almost certainly would skyrocket under our proposal because of the more efficient allocation of assets, the revelation of capital income hidden at present, and the growth of the economy our proposal would ignite," do not seem to me terribly convincing.

There is a second issue worth highlighting as it applies to Piketty as well as COST. While taxes are never popular, there are few taxes so unpopular as wealth taxes. (Fuel taxes might be close.) Many people hate the idea that something that they have invested either time or money in should be taxed at a higher rate because someone else takes a fancy to it. This book is especially radical. It proposes that we should all be obligated to sell at relatively short notice pretty much anything we have to someone who values it more highly than we do. It denounces any one who does not like this idea:

Economists tend to neglect three other impediments to trade: laziness, incompetence, and malice. Private property allows lazy or misanthropic owners to hoard assets and to do so not for gain, but out of sloth. This problem seems to have been particularly prevalent under feudalism, when landowners were not accustomed to prudence, thrift, or hard work. Nobel Laureate John Hicks once wrote, "The best of all monopoly profits is a quiet life."A COST disrupts the quiet life of a lazy monopolist by forcing her to generate the income to sustain a high valuation or turn her assets over to someone who can better use them.

Unfortunately, pretty much all of us are attached to our cars, dwellings, and so forth.
The property tax revolt-Proposition 13in California was driven in large part by income-poor retired people whose homes underwent tremendous capital gains-and who were forced to move because of skyrocketing property taxes. Radical Markets's view is that these people deserve to have their quiet retirement disrupted by facing exactly that choice.

It appears to me-also unfortunatelythat the more efficient a tax is, that is, the harder it is to avoid, the less politically popular it is. We saw that poll taxes (lump sum) in the United Kingdom led to riots, while property taxes led merely to protests. Efficient Pigouvian fuel taxes in France have led to both. It is perhaps time the public finance literature thought more deeply about the political economy of taxes.

As I read this chapter one question I asked myself is how it informs my own research and thinking. Some of the problems they discuss are ones I have worked on. With respect to patents and copyrights where hold-up is indeed an issue, ${ }^{\beta}$ COST would probably eliminate the monopoly. Unfortunately the monopoly is the entire point-it is enforced by the government, so if we want to get rid of it, it is a whole lot easier to abolish it than tax it to death. I have also worked with Holmes and Schmitz (Holmes, Levine, and Schmitz 2012) trying to understand how switchover disruption leads monopolists to be slow to replace old technologies with new ones. I do not see how the radical market proposal helps with this problem.

\section{Chapter 2: Radical Democracy}

Radical democracy is about replacing ordinary voting with either quadratic voting or storable votes or some mix of the two. The two ideas seem to be used as if they are

${ }^{3}$ See Boldrin and Levine (2005). 
interchangeable although they are not. I am not sure how radical this proposal is, but insofar as it would have an effect on large mass elections, I am not convinced it would be a beneficial one. The rationale given by the authors for their proposal is this:

The creators of modern democracies thus built a new political order, but they were uneasy with their handiwork. Failures to protect minority rights, the tyranny of the majority, paradoxical victories for bad candidates, repeated use of majority rule to establish dictatorship, and the tendency of democracy to ignore the views of the very knowledgeable: all reflected the inability of democracy to give consideration to the intensity of people's needs and interests, and to the superior wisdom or expertise of certain voters. There is a better way to allocate resources to people with stronger needs and interests, and reward those who demonstrate special talents or insight-markets.

It is true that democracy seems in many cases to be failing. It is also true that simple voting systems do not register strength of preferences. But does the broad empirical worry and obvious political observation justify the voting changes advocated? Does it make sense to strengthen the voting power of special interest groups in the face of concerns that majority interests are not well represented by the current system?

First, in real voting systems it is costly to turn out, so votes do register to some extent strength of preferences. The close political contest in the United States between the two major parties reflects the fact that the minority party is more willing to turn out then the majority party. ${ }^{4}$ Moreover, an obvious way to modify the system to better

\footnotetext{
${ }^{4}$ For example, in 2004-19 there are about 5.75 percent more voters who lean Democrat than Republican: https:// news.gallup.com/poll/15370/party-affiliation.aspx, while in presidential elections during this period the vote margin was about 2.7 percent. We cannot tell, of course, how many voters crossed party lines, but polling data about voting intentions tell a similar story: https://news.gallup.
}

register strength of preferences is simply to make it more costly to vote-poll taxes, complicated voter registration schemes, voter ID all do this. These are, to put it mildly, very controversial and often the trend is in the opposite direction, to make it easier to vote-in supermarkets, online and so forth. The point is that there is a demand to make every vote equal-the opposite of allowing those with more intense preferences to register them more strongly. This demand is based on ethical and moral considerations: to be persuasive arguments for quadratic or other weighted voting schemes cannot merely point to the consequences of voting systems for outcomes, but need to engage with issues of equity and fairness.

Second, real policies are determined not only by voting but by lobbying. Here it seems that minority views are not so poorly represented. Certainly farmers, bankers, copyright holders, antivaxers, not in my back yard (NIMBY)-ers, and other minority special interests fare well. Some minorities-children, immigrants-do not get to vote, so their views are perhaps not so well represented, but changing the system of voting without enfranchising them is not going to help. When it comes to civil rights, minorities do less well than when it comes to money-Salvatore Modica and I (Levine and Modica 2017) have written about the underlying incentives that lead to this result. On the other hand minorities such as civil and gay rights activists have been very successful in persuading majorities to their cause-and are now generally opposed by minorities. This leads me to worry that further empowering minorities might empower special interests and bigots. Is this a good social goal?

Even if desirable, empowering minorities through some sort of storable/quadratic

com/poll/244199/democrats-match-exceed-republicansturnout-indicators.aspx. 
voting scheme is not a panacea. In 1933 Jews constituted less than 1 percent of the population-it is hard to imagine any voting scheme that would have enabled them to outvote the other 99 percent. The authors somewhat loosely seem to think that some sort of storable/quadratic voting scheme would empower the minority of expertsagain I doubt that experts constitute a large enough fraction of the population that this would be effective.

The issue of experts is important. As someone who has studied voting I wonder: is the problem of minority representation more important than the problem of rational voter ignorance? The 32,000 citations of Downs's (1957) work on rational voter ignorance indicates to me that many do not think so. Is it more important than the problem of special interests and corruption that undermine democracy? Populist movements seem to indicate that many voters do not think so.

At this point let us dig into the details of the authors' proposal. There are two distinct ideas: one is QV, or quadratic voting. In the purest form the voter can purchase votes in a two-issue election but the cost of votes is quadratic in the number of votes cast. The second idea is that of storable votes: a voter has an endowment of votes and can allocate them between different elections or candidates in multiple candidate elections. What the authors refer to by the abbreviation QV is a mix between the two.

To put these ideas in context, let me start with storable votes, where there is a substantial theoretical and empirical literature. ${ }^{\text {. }}$ My takeaway from this literature is that a well-designed storable vote scheme in which some but not all votes are storable is likely to improve decision making in committees of moderate size in which preferences are not too polarized, but turnout is not an issue. I

\footnotetext{
${ }^{5}$ See, for example, Casella (2005); Casella, Gelman, and Palfrey (2006); and Goeree and Li (2008).
}

do not see any indication that anyone working in this area thinks it is some sort of a onesize-fits-all solution to all problems in voting.

Casella and Gelman (2008) suggest that a storable vote type scheme might also be useful when there is an agenda consisting of several referenda. A simple example illustrates why the matter is delicate and why a wellthought-out proposal such as that of Casella and Gelman might work where some sort of vague QV probably would not. Suppose there are two referenda, one on raising pay for prison guards and the other about abortion. Suppose that there are 10,000 voters who are not prison guards, plus ten prison guards. On the prison guard issue, winning is worth $\$ 1,000$ to each guard, with a cost of $\$ 2$ to each of the other voters-so that pay raise has a social cost of $\$ 10,000$ and should not be passed. Suppose on the other hand that prison guards do not care about abortion but the rest of the population is evenly split and values winning at $\$ 1,000$. Each voter gets nine credits, and can split those credits as they wish, with the number of votes cast equal to the square root of the number of credits. Suppose prison guards all cast their votes for higher pay, nine credits and three votes each, so 30 votes for higher pay. Suppose everyone else casts all their votes for their preferred side of the abortion issue, so 15,000 votes on each side. It would be a pretty bad idea for anyone to withdraw even one credit from the abortion election as it would shift a tie to a loss and so cost $\$ 500$ while in no way changing the outcome of the prison guard election. Is this a socially desirable equilibrium? In a standard election prison guards would lose. This highlights why Casella and Gelman make a rather different proposal. They propose bonus votes. That is, everyone votes in every election, but they also have bonus votes that they can allocate to the election of choice. You see how this solves the problem in the example-everyone votes in the prison guard election, and 
the guards do not have enough bonus votes to prevent their defeat.

As QV is a brainchild of one of the authors of the book and as the book does not explain the idea particularly well (mostly with a table showing what the squares of numbers look like), I turned to scientific literature to see what was actually being proposed. Here is what I gleaned from Goeree and Zhang (2017) and Lalley and Weyl (2018). Suppose you can buy voting credits at a utility cost equal to the square of the credits purchased, that there are no liquidity constraints, and that there are $k$ items to vote on with item $j$ worth $v_{j}^{i}$ to voter $i$ and that $\epsilon_{j}$ is the increased probability of winning that comes with a single credit. Let $x_{j}^{i}$ be the credits spent by voter $i$ on item $j$. Hence the objective function is $\sum_{k} \epsilon_{j} x_{j}^{i} v_{j}^{i}-\left(x_{j}^{i}\right)^{2}$ and it follows that therefore that the optimum is $x_{j}^{i}=(1 / 2) \epsilon_{j} v_{j}^{i}$. The case that is well understood is the one in which there are just two items: in this case they necessarily have the same value of $\epsilon_{j}$, so effort is proportional to value so that the item with the highest aggregate value wins.

Unfortunately, the book proposes to extend this idea to settings such as primary elections where there are more than two items. With two items we are guaranteed that the increased probability of one winning is matched by an equal decrease in the probability of the other winning. With more items this is no longer the case and no guarantee that each item $j$ will have the same value of $\epsilon_{j}$. Consequently, effort may no longer be proportional to the value of an item, in which case the item with the highest aggregate value may not win. This is unfortunate because in practice the increased value of winning $\epsilon_{j}$ is the probability of being pivotal. With many candidates in a primary, for example, the chances of being pivotal are orders of magnitude less for candidates who are not among the top two. Hence, there is a coordination problem: nobody will expend much effort on a candidate-no matter how good-unless other voters are willing to do the same. In fact, we have some pretty good systems for dealing with the coordination issue with multiple candidates: in French general elections and California primary elections, for example, the top two vote getters in the first round go to a run-off. The theory tells us in this case that only the top three candidates matter since none of the others have a chance of making the run-off. And indeed, in the recent French general election, the top three candidates not only received almost all of the votes, but the race between second and third was quite close.

I do not want to take a strong stand on storable votes versus QV versus standard voting or their application in elections, nor should the authors be pushing this idea, and for the same reason-the evidence is not yet in. To give an example, in a recent experimental study Casella and Sanchez (2019) compared a bonus vote scheme to a QV scheme for a large election with four issues. Both worked reasonably well at improving minority success and QV did indeed improve efficiency. On the other hand: the setting (Mturk) was one where there was no possibility of party voting, and the four issues were specifically chosen to be ones of similar importance on which opinion was relatively divided. A simple one-size-fits-all scheme would not achieve this in practice.

Although the authors focus on pivotal voting, for large elections the literature has turned to models of costly party turnout. ${ }^{6}$ In these models it is parties through party leaders or collective decision making that determine turnout. In the simplest case parties bid costly votes in an all-pay auction. From the utility point of view this is the same as a second price auction, so the party that most

\footnotetext{
${ }^{6}$ For models with costly turnout and collective decision making see Levine and Mattozzi (2015). For ethical voter models see Feddersen and Sandroni (2006) and Coate and Conlin (2004).
} 
highly values winning the election receives the utility from winning minus the cost of matching the bid of the losing party. Here, clearly, strength of opinion matters, and how that might work together with a quadratic or storable vote scheme is unclear. ${ }^{7}$ The irony is that party models may be more akin to committee voting than large elections with pivotal voters - so indeed a bonus vote scheme might be a good one.

The application of mechanism design to large problems of political economy is important, but it is also complicated. Except on the then-contentious issue of slavery, the US Constitution was well thought out, improved upon, and has stood the test of time well. Poorly thought out institutions do not fare so well. The half-baked Brexit referendum allowed 35 percent of the population to force a dramatic change from existing and well functioning institutions to an unknown alternative. This came about because of the previous ill-thought-out 1975 decision by parliament to allow referenda for the first time. Given that the issue-joining the European Union-was a major institutional change, a referendum in this context made sense. Using a "nonbinding" referendum that was nonetheless viewed as binding without clear rules for repeal or future referenda was not a good innovation. That referendum was about a specific issue and passed by a two-third majority. It is now interpreted as making legitimate referenda over unclear but dramatic institutional changes that are taken as binding if passed even by a slender majority. One wonders what unanticipated catastrophes would be occur if QV were introduced in a similarly insouciant way.

I think there is rightfully a lot of enthusiasm among people working in the field for the potential of storable voting and related schemes. With the exception of the authors,

${ }^{7}$ A step in this direction is Kaplow and Kominers (2017). people I have spoken with share my view that far more research on how these systems work is needed before they might be introduced into widespread practice.

\section{Chapter 3: Uniting the World's Workers}

The third chapter of the book switches to the fraught issue of globalization. It argues that the solution is more permissive immigration laws. That appears be difficult to implement in the current political environment in most countries. Reading the authors' proposal carefully, however, their proposal is actually for more restrictive immigration laws so perhaps it will gain some traction. This is especially the case as their main concern is not with migrants at all:

While migration offers enormous advantages to the migrants themselves and their families back home, to employers and owners of capital, and to the high-skilled workers who they complement and live among, migration offers few benefits to and imposes some costs on most workers in wealthy countries, who are already left behind by the forces of trade, automation, and the rising power of concentrated finance.

The solution to this problem involves an auction. They suggest a modified form of auctioning off work visas. Hence the beneficiaries (migrants) would pay those left behind by "the forces of trade, automation, and the rising power of concentrated finance."

As it happens some of the biggest problems with immigration revolve around existing and not prospective immigrants. This they address:

Existing illegal migrants would have to be fit into the system through a combination of a one-time amnesty with a path to citizenship, finding sponsors, or being deported. Enforcement against future illegal migrants would have to be more stringent to avoid undermining the rights of both the large new class of legal migrants and their hosts. 
I think there is pretty widespread agreement that one of the "path to citizenship" or "being deported" is a good idea-the debate seems to be over which is the good idea. The authors views seem to lean on the side of the hawks:

... immigration enforcement would need to be strengthened ... Enforcement against future illegal migrants would have to be more stringent ... No legal reform can be effective unless it is enforced.

Fortunately, their auction would mitigate things as "migrants desperate to enter the country can more easily...avoid the risks of illegal entry." The plan of letting more people enter legally and cracking down on illegal immigration is not particularly radical, but it does not seem to have widespread support.

Turning to the actual plan of auctioning off visas, this has, as they say, worked well for au pairs. Their strongest evidence is this:

The migration systems in the UAE, Qatar, Kuwait, Bahrain, Oman, and Saudi Arabia (countries of the Gulf Cooperation Council, or GCC) are often criticized, but they tell an interesting tale. Where the United States has roughly nine natives for every foreign-born resident, the ratio in the $\mathrm{UAE}$ is reversed. Bahrain and Oman host roughly one migrant for every native. In Saudi Arabia, the GCC country with the fewest migrants per native, there is one migrant for every two citizens.

The focus on au pairs and the Gulf States is not a coincidence. In both cases the workers are not migrants, they are temporary workers. Temporary workers-such as seasonal farm workers-generally reside in a different country to which they return and are not terribly controversial. Immigrants are people who come-and after a time set down roots and want to stay. It is the staying that is the political issue. As the focus on temporary workers indicates, this book has little to contribute to this issue-and indeed, it is not clear to me in what way the proposal in the chapter helps to unite the world's workers.

As the chapter is supposedly about globalization, I do wonder if it has the right priorities: many poor countries would benefit more from a reduction in agricultural trade protection by rich countries than from being able to export a few more of their most able individuals.

\section{Chapter 4: Dismembering the Octopus}

The fourth chapter is the best of the book, and as a result I have not so much to say about it: it makes a decent although not particularly radical proposal. I urge you to read it.

The idea is that institutional investors, by taking positions in rival firms, promote oligopolistic practices. They present some evidence on this point and it seems plausibly true. I am not convinced as they are that this is "the" problem in the economy, but it seems worth doing something about.

The proposal in the book-sadly lacking an acronym-is the obvious one of placing restrictions on how institutional investors are allowed to distribute their investments within an industry. The devil is in the details, but it is surely worth working those out.

\section{Chapter 5: Data as Labor}

Every group-farmers or computer programmers-have their pet peeves with the world. I am far from convinced that all of these peeves constitute earth-shattering social problems. Hence when it comes to the ownership of our data on Facebook-which we voluntarily allow them to use in exchange for providing us with the platform-I cannot work up an excitement. Fortunately the authors can, so I will follow their lead:

This arrangement, in which users take advantage of services and the company gains all the 
upside of the data they generate, may sound novel, but it is actually very old. Prior to the rise of capitalism, feudal labor arrangements worked similarly. Lords insulated their serfs from fluctuations in markets and guaranteed them safety and traditional rights to use the land and to keep enough of their crop to survive. In exchange, lords took all the upside of the market return on serfs' agricultural output. Similarly, today, siren servers provide useful and enjoyable information services, while taking the market value of the data we produce in exchange. We thus refer to this contemporary system as "technofeudalism."

This is a strong claim: that a voluntary arrangement by which we allow the use of our data in exchange for valuable services is akin to a feudal system in which serfs are bound to the land by the threat and actuality of violence. Do the authors back up this claim?

The chapter is not terribly well organized, but I extract four themes from it, none of which back up this claim. The first theme is that, empirically, we are exploited by the powerhouses of the digital economy because they are highly profitable. The second is that the payment in services, rather than money, represents a kind of exploitation. The third is that the market power of these firms is based on artificial intelligence and there is a natural monopoly because of increasing returns to the ownership of data. The final theme is that the solution to the problem of exploitation is a kind of a trade union of digital economy users who will negotiate for monetary payments in exchange for the provision of data.

Before running through these four themes, let me reiterate that even if we accept the authors' arguments on all four points, they scarcely amount to "technofeudalism." Setting their hyperbole aside, what do we make of their arguments? First, is it true that the profits of the digital powerhouses amount to exploitation?

The powerhouses of the digital economy, firms like Facebook, Google, and Microsoft, exploit the lack of public understanding of AI [artificial intelligence] and ML [machine learning] to collect for free the data we all leave behind in our online interactions. This is the source of the record profits that make them the most valuable companies in the world. Facebook, for example, pays out only about $1 \%$ of its value each year to workers (programmers) because it gets the rest of its work for free from us! In contrast, Walmart pays out $40 \%$ of its value in wages. People's role as data producers is not fairly used or properly compensated. This means that the digital economy is far behind where it should be, that the income from it is distributed to a small number of wealthy savants rather than to the masses, and that many of us have a false fear of AI creating mass unemployment when humans are more necessary than ever to our digital economy.

The final part of this seems to be a nonsequitur, conflating as it does knowledge about me with my labor. Moreover, the computation that 99 percent of value is generated from the rest of us is misleading. In 2019 (data from Statista) Facebook generated $\$ 22$ billion in net income from $\$ 56$ billion in revenue-indicating costs considerably higher than 1 percent of revenue. But this was exceptional because for many years Facebook generated considerably less net income: from 2007 to 2014 the highest net income generated by Facebook was $\$ 3$ billion: the very high net income in recent years should be seen as it is: as a return to investment made in earlier years, not as exploitation of us.

Turning to the second theme, does payment in services rather than money represent a kind of exploitation? Consider first what the digital powerhouses do with our data: they make recommendations, primarily about things we might wish to purchase. In my experience they do not make terribly useful recommendations, but as they profit from it perhaps other people find differently. These recommendations are based on data about us, but also data about 
others. Hence the digital powerhouses provide a service: they use data about you to make recommendations valuable to me. In exchange, they use my data to make valuable recommendations to you. Is it obvious which way the money should flow? That they should pay me for my data rather than me paying them for the valuable service? Or perhaps I should pay you? These considerations are even more significant when it comes to self-driving cars: is it obvious that providers of self-driving cars should pay me for data about my driving habits rather than me paying them for the safe transportation I derive from their knowledge of your driving habits?

That the digital powerhouses make their money through advertising and the provision of free services is not a new business model: for decades the television industry in the USA did exactly this. While there were concerns about the resulting industry concentration, today we look back on that era with nostalgia for the good old days where the worker made a decent wage, and not as a sad period of television feudalism.

Finally, I should indicate that there is a certain degree of ambiguity in the authors' argument that payment in services rather than money represents exploitation.

Second, as highlighted by economist Roland Bénabou and Nobel Laureate Jean Tirole in their incisive 2003 and 2006 analyses of situations like the Tom Sawyer problem, paying for an activity often undermines intrinsic motivations (such as entertainment and social pressure). Paying for online data provision may signal to users that the activities they currently view as entertainment are actually labor benefiting the siren servers and for which they should demand payment, undermining the entertainment value. Paying may also undermine the perceived motives of social collaboration and participation that may yield social rewards to users for "being part of an online community." On a darker side, paying may also undermine the stickiness of content as it "breaks the spell" of online entertainment by making clearer the nature of the economic relationship.

I should indicate that the Bénabou and Tirole paper is a purely theoretical paper containing evidence for nothing. There are empirical claims in this direction, such as Gneezy and Rustichini (2000), and if the authors wish to make an empirical point they should refer to empirical results. I am not sure exactly what conclusion the authors want us to draw from this, as it seems to contradict their earlier argument that payment in kind is a bad thing.

While the authors do not examine any evidence for their claims, there is some evidence against them: there are plenty of data peons making money off the internet. A prominent and relevant example is the online gaming market-online games are platforms much as is Facebook. There is also a market for watching star players play. The platform for that is called "Twitch." Star players support themselves through the earnings they make from game playing: "A Twitch streamer with 2,000 subscribers can earn an extra $\$ 5,000$ a month" $"$ on top of endorsements, salary, and prize money. These gamers are able to earn a living - some stars become rich even-without "breaking the spell" of online entertainment-and indeed without any help from the authors of this book. But when did the fact that sports stars get paid start to interfere with our enjoyment of sports?

The third theme of the chapter is that there are increasing returns to scale in artificial intelligence.

Early ML systems for speech recognition achieved gains in accuracy more quickly than did later systems. However, a speech recognition system with all but very high accuracy is mostly useless, as it takes so much time for the user to correct the errors it makes. This means

\footnotetext{
${ }^{8}$ https://info.jkcp.com/blog/professional-gamersalary-esports/.
} 
that the last few percentage points of accuracy may make a bigger difference for the value of a system than the first 90 percent does. The marginal value grows to the extent that it allows this last gap to be filled.

This sounds like a fairly classical production technology with U-shaped average cost: initially increasing returns followed by eventually decreasing returns. Nevertheless, as they say, "If this is true, then data may actually have increasing rather than diminishing returns." I think it is a pretty rough to build an entire radical utopian proposal because of something that "may actually" be true.

Machine learning and large data or not, there seems to be a consensus that the big platforms benefit from a different form of increasing returns — a network externality. So we may well ask: do increasing returns pose a particular problem in the "data" industry not present in earlier industries? Take the emerging market for self-driving cars. Does this look different from the original market for cars or airplanes? In both of those industries there were initially many different competing firms followed eventually by consolidation resulting in a few surviving firms. Currently, the self-driving car industry looks like the early stages of the car and airplane industry: "Some of the 52 different companies that have been approved by the California Department of Motor Vehicles to test autonomous vehicles on the road include Apple, Waymo, Tesla, Ford, Honda, BMW, Nissan, Intel, and Uber." the case in automobiles and airplanes, there will be a shakeout and only a handful of firms will survive in the long run. While industry concentration is a concern in automobiles and airplanes, it seems a modest one-and indeed there are substantial indications of competition in both industries as firms

\footnotetext{
9 https://abcnews.go.com/beta-story-container/ US/companies-working-driverless-car-technology/ story?id=53872985.
}

rise and decline-consider for example the replacement of Lockheed in the commercial aviation industry by Airbus, or the decline of General Motors.

By comparison to building cars or airplanes, software is cheap. Despite the authors' claims, it does not appear that acquiring the data to build an effective voice recognition system is that difficult: what is regarded as currently the best voice recognition software is not provided by Google, Amazon, or Apple, but by a relatively small company, Nuance software..$^{10}$ This cheapness of software is reflected in the fact that competition in the software industry appears to be substantial: how many years has it been since it was Microsoft and not Facebook we were afraid of? I, at least, am old enough to remember when IBM was going to rule the world.

Finally, it is wrong to think that the digital powerhouses have a monopoly on our data. If you wish you can download everything you have ever done on Facebook in a convenient machine readable format. If someone would provide the software (and this is not a big job), you could upload that data to an alternative provider and convince your friends to do the same, thereby recreating your social network on a different platform. Rather than ranting about technofeudalism, I wonder if it would not be more productive to direct computer-illiterate politicians away from futile efforts to break up large multinational firms, and instead promote greater competition by encouraging alternative platforms?

Coming finally to the fourth theme: the plan for solving data peonage. This is rather less well developed than their other proposals:

It may be time for "data workers of the world (to) unite" into a "data labor movement." A

\footnotetext{
${ }^{10} \mathrm{See}$, for example, the review of voice recognition software https://www.techradar.com/best/best-voice-recognitionsoftware in Techradar.
} 
striking feature of the data labor market is that it is an international market, one that is almost completely unaffected by borders and government regulation. Once people awaken to their role as data laborers-obtain a "class consciousness," if you will—organizations (sort of like unions) may emerge to supply data laborers with the means to engage in collective action. Imagine, for example, a data labor union that solicited members - the data laborersby promising them higher payments for their data. Once the union obtained a critical mass, it could approach Facebook or Google and threaten a "strike" (also, effectively, a boycott because data laborers are simultaneously consumers of Facebook's and Google's services). The technical details would be complex, but we can imagine a range of possible approaches.

If only.

\section{The Bottom Line}

The authors have a message. Market design is great and it is easy. Markets are sloppy affairs: sometimes buyers post prices, sometimes sellers, some goods are sold at auction, others on exchanges ... some are even sold (sniff, sniff) through bargaining. We can fix this: we'll replace all of these nasty old markets with a simple clean government run auction. The poor will become rich and the rich will have to work for a living!

I have a message. Market design is great and it is hard. Allocating oil leases is not the same as allocating the radio spectrum. Thick markets are not the same as thin markets. Auctions are complicated. Private information may lie on the buyer side, on the seller side, or both. Real market designers know this. They tailor solutions to problems: having designed an algorithm for allocating residents to hospitals and faced with the problem of matching kidney donors to patients they did not blindly claim to have solved that problem, but instead dug into the details and designed an algorithm for the kidney matching problem. Real market designers sweat the details: they improve lives and prosperity. Listen to real market designers.

\section{REFERENCES}

Boldrin, Michele, and David K. Levine. 2005. "The Economics of Ideas and Intellectual Property." Proceedings of the National Academy of Sciences of the United States of America 102 (4): 1252-56.

-Casella, Alessandra. 2005. "Storable Votes." Games and Economic Behavior 51 (2): 391-419.

-Casella, Alessandra, and Andrew Gelman. 2008. "A Simple Scheme to Improve the Eficiency of Referenda." Journal of Public Economics 92 (10-11): 2240-61.

Casella, Alessandra, Andrew Gelman, and Thomas R. Palfrey. 2006. "An Experimental Study of Storable Votes." Games and Economic Behavior 57 (1): 123-54.

Casella, Alessandra, and Luis Sanchez. 2019. "Storable Votes and Quadratic Voting: An Experiment on Four California Propositions." NBER Working Paper 25510.

Coate, Stephen, and Michael Conlin. 2004. "A Group Rule: Utilitarian Approach to Voter Turnout: Theory and Evidence." American Economic Review 94 (5): 1476-504.

Cramton, Peter, Robert Gibbons, and Paul Klemperer. 1987. "Dissolving a Partnership Efficiently." Econometrica 55 (3): 615-32.

Diamond, Peter A. 1998. "Optimal Income Taxation: An Example with a U-shaped Pattern of Optimal Marginal Tax Rates." American Economic Review 88 (1): 83-95.

Downs, Anthony. 1957. "An Economic Theory of Political Action in a Democracy." Journal of Political Economy 65 (2): 135-50.

-Feddersen, Timothy, and Alvaro Sandroni. 2006. "A Theory of Participation in Elections." American Economic Review 96 (4): 1271-82.

Fudenberg, Drew, David K. Levine, and Jean Tirole. 1985. "Infinite-Horizon Models of Bargaining with One-Sided Incomplete Information.” In Game-Theoretic Models of Bargaining, edited by Alvin E. Roth, 73-98. Cambridge: Cambridge University Press.

-Gneezy, Uri, and Aldo Rustichini. 2000. "A Fine Is a Price." Journal of Legal Studies 29 (1): 1-17.

Goeree, Jacob K., and Nixon Li. 2008. "Inefficient Voting." http://citeseerx.ist.psu.edu/viewdoc/download;jsessionid=A6D375DB527E9B8A0B6E2758697FD943? doi=10.1.1.192.4763\&rep=rep1\&type $=$ pdf.

-Goeree, Jacob K., and Jingjing Zhang. 2017. "One Man, One Bid." Games and Economic Behavior 101: $151-71$.

Gul, Faruk, Hugo Sonnenschein, and Robert Wilson. 1986. "Foundations of Dynamic Monopoly and the Coase Conjecture." Journal of Economic Theory 39 (1): 155-90. 
Haeringer, Guillaume. 2017. Market Design. Cambridge: MIT Press.

-Harberger, Arnold C. 1962. "The Incidence of the Corporation Income Tax." Journal of Political Economy 70 (3): 215-40.

Harberger, Arnold C. 1965. "Issues of Tax Reform for Latin America." In Fiscal Policy for Economic Growth in Latin America: Papers and Proceedings of a Conference on Fiscal Policy for Economic Growth in Latin America Held in Santiago, Chile, Dec. 1962, under the Auspices of the Joint Tax Program of the Organization of American States, the Inter-American Development Bank, and the United Nations Economic Commission for Latin America. Baltimore: Johns Hopkins University Press.

Heller, Michael. 2008. The Gridlock Economy: How Too Much Ownership Wrecks Markets, Stops Innovation, and Costs Lives. New York: Basic Books.

-Holmes, Thomas J., David K. Levine, and James A. Schmitz. 2012. "Monopoly and the Incentive to Innovate When Adoption Involves Switchover Disruptions." American Economic Journal: Microeconomics 4 (3): 1-33.

Kaplow, Louis, and Scott Duke Kominers. 2017. "Who Will Vote Quadratically? Voter Turnout and Votes Cast under Quadratic Voting." Public Choice 172 (1-2): 125-49.

Lalley, Steven P., and E. Glen Weyl. 2018. "Quadratic
Voting: How Mechanism Design Can Radicalize Democracy." AEA Papers and Proceedings 108: 33-37.

Levine, David K., and Andrea Mattozzi. 2015. "Voter Turnout with Peer Punishment." http://www. dklevine.com/archive/refs4786969000000001401. pdf.

Levine, David K., and Salvatore Modica. 2017. "Size, Fungibility, and the Strength of Lobbying Organizations." European Journal of Political Economy 49: 71-83.

-Mirrlees, J. A. 1971. "An Exploration in the Theory of Optimum Income Taxation." Review of Economic Studies 38 (2): 175-208.

Piketty, Thomas. 2014. Capital in the 21st Century. Cambridge and London: Belknap Press.

-Piketty, Thomas, and Emmanuel Saez. 2013. "A Theory of Optimal Inheritance Taxation.” Econometrica 81 (5): 1851-86.

Prescott, Edward C. 2004. "Why Do Americans Work So Much More Than Europeans?" NBER Working Paper 10316.

-Restuccia, Diego, and Richard Rogerson. 2017. “The Causes and Costs of Misallocation." Journal of Economic Perspectives 31 (3): 151-74.

Statista. "Facebook-Statistics and Facts." https://www. statista.com/topics/751/facebook/ 